\title{
The pattern electroretinogram in glaucoma and ocular hypertension
}

\author{
E O'Donaghue, G B Arden, F O'Sullivan, F Falcão-Reis, B Moriarty, R A Hitchings, \\ W Spilleers, C Hogg, G Weinstein
}

\begin{abstract}
Thirty one eyes with established glaucoma, 61 high risk ocular hypertensive (OHTs) eyes, 66 medium risk OHT eyes, 58 low risk OHT eyes, and 47 control eyes have been followed for up to 2 years by clinical examination and pattern electroretinography (PERG). The study was 'masked' so electrophysiological and clinical data were kept separate. Criteria have been devised which enable PERG measurements to distinguish all established glaucomatous eyes from all normal controls; these criteria demonstrate abnormalities in some OHT eyes, particularly those at high risk. The PERG abnormality is greatest in eyes with established glaucoma in which the intraocular pressure has been lowered by treatment. The PERG becomes smaller as the degree of clinical abnormality increases. Test-retest variability of the PERG is sufficiently low to ensure that most of those first described as abnormal continue to be so.
\end{abstract}

The Electrodiagnosis and Glaucoma Departments of Moorfields Eye Hospital, City Rd, London EC1 E O'Donoghuet G B Arden F O'Sullivan F Falcão-Reis* B Moriartyt R A Hitchings W Spilleers\$ C Hogg

G Weinstein

Present addresses $\star$ Department of Ophthalmology, Oporto Medical School, Av Prof Hernani Monteiro, 4200 Oporto, Portugal;

tDepartment of Ophthalmology, The Eye Hospital, Manchester. England; $\$$ Department of Ophthalmology, KU Leuven, Kapucijnenvor B-3000 Leuven, Belgium; If Department of Ophthalmology, West Virginia University, Morgantown, West Virginia, USA.

Correspondence to: G B Arden.

Accepted for publication 12 December 1991
The standard definition of glaucoma (raised intraocular pressure (IOP) changes in the disc and a characteristic field defect) cannot be made until a considerable proportion of the ganglion cells in the retina are dead. ' However, it is known that by the time the diagnosis is made, the underlying condition of ocular hypertension (OHT) may have been present for up to 10 years $^{23}$ so the diagnosis records an arbitrary point (determined by the sensitivity of the diagnostic methods) in a continuing decline. There have been two recent reports ${ }^{t 5}$ which suggest that treatment of glaucoma suspects, begun earlier, reduces IOP and in follow-up, the rate of development of scotomata decreases, compared with untreated OHT. It is therefore possible that by treating OHT itself, and not waiting for diagnosis by perimetric means, the appearance of scotomata could be largely prevented. The problem with this suggestion is that there are a very large number of patients with OHT, and only a small proportion will develop field defects in the near future. ${ }^{23}$ Universal treatment is therefore most undesirable. What is required is a means of detection of lesser degrees of functional defect than is possible with perimeters. Some tests proposed to fill this gap (measurement of defects in the nerve fibre layer for example) require considerable skill to record and to interpret. ${ }^{678}$ They record structural retinal or optic nerve damage. It would be desirable to develop functional tests to measure very small changes from normal.

First reports have suggested that this requirement is fulfilled by an objective electrophysiological test of visual function, the pattern electroretinogram (PERG). ${ }^{9-22} \mathrm{We}$ and others have shown that the PERG is abnormal in patients with established glaucoma. In addition, colour vision tests appear to discriminate between normals and patients with glaucoma. ${ }^{23} 24$ What is required is a prolonged and careful investigation into the progress of the disease as monitored by these tests in a larger cohort. The aim to establish whether the tests can be used in the management of patients with various grades of OHT. We report below on results with the PERG (another paper describes results obtained by testing macular colour vision). ${ }^{25}$

\section{Methods}

\section{RECRUITMENT}

We aimed to recruit approximately equal numbers of patients with established glaucoma, high risk, medium risk, and low risk glaucoma suspects, and normal subjects. The glaucoma patients were recruited from the glaucoma clinic: all eyes had typical reproducible glaucomatous field defects. The glaucoma suspects were classified as high, medium, or low risk according to the level of their IOP and cup:disc ratio (CC:D) (see Table 1 for exact criteria). Yablonski has shown that these groups have different rates of conversion to glaucoma and that the higher the IOP and the C:D ratio the greater is the risk of developing glaucoma. ${ }^{26}$ Recruitment of patients with established glaucoma and glaucoma suspects was performed by a clinical fellow who was not concerned with the PERG testing. The normal subjects were recruited from patients'

\section{Table 1 Criteria for classification of glaucoma suspects}

\begin{tabular}{|c|c|c|c|c|}
\hline$I O P(\mathrm{~mm} \mathrm{Hg})$ & & & $C: D$ ratio & Perimetry \\
\hline $\begin{array}{l}\text { Normals } \\
\text { Low risk } \\
\text { Medium risk } \\
\text { High risk } \\
\text { Glaucoma }\end{array}$ & $\begin{array}{l}<21 \\
<26 \\
>26 \\
>26 \\
\text { Any }\end{array}$ & $\begin{array}{l}\text { or } \\
\text { and }\end{array}$ & $\begin{array}{l}<0.6 \\
<0.6 \\
>0.6 \\
>0.6 \\
>0.6\end{array}$ & $\begin{array}{l}\text { Normal } \\
\text { Normal } \\
\text { Normal } \\
\text { Normal } \\
\text { Abnormal }\end{array}$ \\
\hline
\end{tabular}

Abnormal perimetry was defined as 3 or more adjacent points depressed by $5 \mathrm{db}$ or more and reproduced on 3 occasions. 
Figure 1 Diagram of normal transient PERGs illustrating how measurements of negative and positive waves were made.

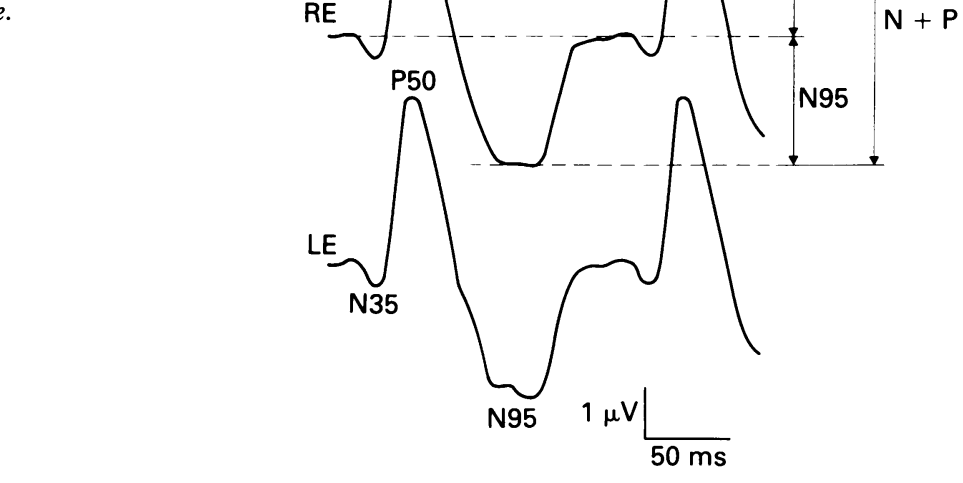

spouses, hospital staff, and subjects referred to other hospital departments with minor uniocular complaints and essentially normal examination results. Thus, one eye was chosen from each normal subject for testing.

\section{EXCLUSIONS}

Patients were excluded if they suffered from other eye disease or severe systemic disease. Patients' eyes with visual acuity $<6 / 9$ were excluded: these failures were due to cataract, amblyopia, or other uniocular conditions. Four individuals who failed to attend the follow-up were also excluded. By December 1990, 31 glaucoma eyes from 21 subjects, 61 high risk eyes from 41 subjects, 66 medium risk eyes from 43 subjects, 58 low risk eyes from 33 subjects, and 47 normal eyes from 47 subjects had been recruited to this study and examined as described below over a minimum period of 1 year. Sixty

Table 2A Mean values of four PERG parameters for the right eyes of glaucoma patients, high, medium, and low risk suspects. Also mean values of PERG parameters in 47 normal eyes

\begin{tabular}{|c|c|c|c|c|c|c|c|c|}
\hline Class & Eyes $(n)$ & Subjects (n) & Age & & P50 & $N 95$ & $N / P$ & $N+P$ \\
\hline Glaucoma & 15 & 15 & $\begin{array}{l}\text { Mean } \\
\text { SD }\end{array}$ & $\begin{array}{l}56 \\
15\end{array}$ & $\begin{array}{l}1.53 \\
0.66\end{array}$ & $\begin{array}{l}0.23 \\
0.28\end{array}$ & $\begin{array}{l}0.16 \\
0.21\end{array}$ & $\begin{array}{l}1.77 \\
0.73\end{array}$ \\
\hline High risk & 30 & 30 & $\begin{array}{l}\text { Mean } \\
\text { SD }\end{array}$ & $\begin{array}{l}55 \\
10\end{array}$ & $\begin{array}{l}2 \cdot 29 \\
0 \cdot 80\end{array}$ & $\begin{array}{l}0.94 \\
0.74\end{array}$ & $\begin{array}{l}0.39 \\
0.26\end{array}$ & $\begin{array}{l}3.26 \\
1.33\end{array}$ \\
\hline Medium risk & 31 & 31 & $\begin{array}{l}\text { Mean } \\
\text { SD }\end{array}$ & $\begin{array}{l}54 \\
10\end{array}$ & $\begin{array}{l}2 \cdot 15 \\
0.79\end{array}$ & $\begin{array}{l}1 \cdot 18 \\
0.77\end{array}$ & $\begin{array}{l}0.57 \\
0.35\end{array}$ & $\begin{array}{l}3.32 \\
1.28\end{array}$ \\
\hline Low risk & 30 & 30 & $\begin{array}{l}\text { Mean } \\
\text { SD }\end{array}$ & $\begin{array}{l}56 \\
11\end{array}$ & $\begin{array}{l}2.54 \\
0.89\end{array}$ & $\begin{array}{l}1.08 \\
0.78\end{array}$ & $\begin{array}{l}0.44 \\
0.34\end{array}$ & $\begin{array}{l}3.66 \\
1.25\end{array}$ \\
\hline Normals & 47 & 47 & $\begin{array}{l}\text { Mean } \\
\text { SD }\end{array}$ & $\begin{array}{l}41 \\
11\end{array}$ & $\begin{array}{l}2.97 \\
0.77\end{array}$ & $\begin{array}{l}1.39 \\
0.62\end{array}$ & $\begin{array}{l}0.48 \\
0.21\end{array}$ & $\begin{array}{l}4 \cdot 36 \\
1 \cdot 12\end{array}$ \\
\hline
\end{tabular}

NB The ratios N/P are the means of the individual values; they are not therefore identical to the ratios of the means shown in the columns to the left. Also note that only one eye of each normal subject was tested; therefore the normal values are identical in Tables $2 \mathrm{~A}$ and $2 \mathrm{~B}$.

Table 2B Mean values of PERG parameters for the left eyes of glaucoma patients, high, medium, and low risk suspects. Also mean values of $P E R G$ parameters in 47 normal eyes

\begin{tabular}{|c|c|c|c|c|c|c|c|c|}
\hline Class & Eyes (n) & Subjects $(n)$ & Age & & P50 & $N 95$ & $N / P$ & $N+P$ \\
\hline Glaucoma & 16 & 16 & $\begin{array}{l}\text { Mean } \\
\text { SD }\end{array}$ & $\begin{array}{l}55 \\
14\end{array}$ & $\begin{array}{l}1.43 \\
0.47\end{array}$ & $0 \cdot 13$ & 0.09 & $\begin{array}{l}1.57 \\
0.53\end{array}$ \\
\hline High risk & 31 & 31 & $\begin{array}{l}\text { SD } \\
\text { Mean } \\
\text { SD }\end{array}$ & $\begin{array}{l}14 \\
55 \\
10\end{array}$ & $\begin{array}{l}0.47 \\
2.09 \\
0.91\end{array}$ & $\begin{array}{l}0.16 \\
0.64 \\
0.52\end{array}$ & $\begin{array}{l}0.12 \\
0.31 \\
0.27\end{array}$ & $\begin{array}{l}0.53 \\
2.77 \\
1.13\end{array}$ \\
\hline Medium risk & 35 & 35 & $\begin{array}{l}\text { Mean } \\
\text { SD }\end{array}$ & $\begin{array}{l}56 \\
12\end{array}$ & $\begin{array}{l}2 \cdot 21 \\
0.80\end{array}$ & $\begin{array}{l}1.24 \\
0.79\end{array}$ & $\begin{array}{l}0.61 \\
0.52\end{array}$ & $\begin{array}{l}3.45 \\
1.27\end{array}$ \\
\hline Low risk & 28 & 28 & $\begin{array}{l}\text { Mean } \\
\text { SD }\end{array}$ & $\begin{array}{l}56 \\
11\end{array}$ & $\begin{array}{l}2.49 \\
0.76\end{array}$ & $\begin{array}{l}0.98 \\
0.84\end{array}$ & $\begin{array}{l}0.40 \\
0.36\end{array}$ & $\begin{array}{l}3 \cdot 47 \\
1 \cdot 17\end{array}$ \\
\hline Normals & 47 & 47 & $\begin{array}{l}\text { Mean } \\
\text { SD }\end{array}$ & $\begin{array}{l}41 \\
11\end{array}$ & $\begin{array}{l}2.97 \\
0.77\end{array}$ & $\begin{array}{l}1.39 \\
0.62\end{array}$ & $\begin{array}{l}0.48 \\
0 \cdot 21\end{array}$ & $\begin{array}{l}4 \cdot 36 \\
1 \cdot 12\end{array}$ \\
\hline
\end{tabular}

NB The ratios N/P are the means of the individual values; they are not therefore identical to the ratios of the means shown in the columns to the left. eyes from 138 patients were excluded on the grounds indicated above.

\section{CLINICAL TESTS}

All patients were examined every 6 months. At each visit visual acuity, applanation tonometry, and full clinical examination of fundus and disc were carried out. Perimetry was carried out with the Humphrey perimeter, program 24/II, and analysed statistically. In all cases disc photographs were taken annually both in full colour and in red-free light. A fasting blood glucose test was performed on the first visit to identify any subject with diabetes mellitus. If this diagnosis was subsequently confirmed, the patient was excluded from the special tests.

\section{SPECIAL TESTS}

Patients were referred to the electrodiagnostic department for PERG testing. No clinical information was sent with the patients. The technique for recording PERGs has been described previously. ${ }^{91722}$ The PERG was recorded bilaterally, using gold foil corneal electrodes and a reference electrode on the skin near the lateral canthus. The stimulus subtended $16 \times 22^{\circ}$ and the pattern reversing checks were of $30^{\prime}$ subtense and near $100 \%$ contrast. There were six reversals per second. About 250 sweeps were averaged for a response; four or more responses were recorded. The initial corneal positive response (P50) and the later cornea negative response (N95) were measured separately (see Fig 1). In addition, in many of the patients' PERGs were recorded with reversals every $60 \mathrm{~ms}$ to obtain a 'steady state' response, which approximates to a sine wave. ${ }^{2127}$ The time base was lengthened to $180 \mathrm{~ms}$, so three consecutive cycles of response could be visualised during the averaging. Records were obtained with the whole screen exposed $\left(16 \times 22^{\circ}\right)$ and also with an $11^{\circ}$ opaque disc placed at the screen centre to remove the stimulus from the central $27 \%$ of the retina previously stimulated. Colour contrast sensitivity tests were carried out as described in the accompanying paper. ${ }^{25}$

Tests were carried out by technicians who measured the results. This was cross checked by one of us, who also made the (rare) decision that some results had to be discarded. This occurred if there was inadequate documentation, or internal evidence of inconsistency and poor recording: the most common causes of the latter are mains artefacts and epiphora. Electrodiagnostic reports were entered into the patients' files but were not used in management. Results were entered into a database by the technicians, and again these were rechecked, and a number of anomalous results found to be due to entry errors. At a different time, clinical results were entered, under the supervision of the clinical fellow and entry errors removed by rechecking. Although the clinical fellow was aware of the relationship between all results, apart from this the study was masked and decisions about treatment of patients' eyes were made by persons other than those involved in the tests.

In an attempt to quantify the reproducibility 
Table 3 Means and significance of differences between the results from the right eyes of all the patients and normals in the cohort, separated by risk class

\begin{tabular}{|c|c|c|c|c|c|c|c|c|c|c|c|c|c|c|c|c|c|}
\hline \multirow{2}{*}{$\begin{array}{l}\text { Category } \\
\text { Component }\end{array}$} & & \multicolumn{4}{|c|}{ Low risk } & \multicolumn{4}{|c|}{ Medium risk } & \multicolumn{4}{|c|}{ High risk } & \multicolumn{4}{|c|}{ Glaucoma } \\
\hline & & P50 & N95 & $(N+P)$ & $N / P$ & P50 & N95 & $(N+P)$ & $N / P$ & P50 & N95 & $(N+P)$ & $N / P$ & P50 & N95 & $(N+P)$ & $N / P$ \\
\hline $\begin{array}{l}\text { Normal } \\
\text { Low risk } \\
\text { Medium risk } \\
\text { High risk }\end{array}$ & $\begin{array}{l}t \\
\mathrm{df} \\
t \\
\mathrm{df} \\
t \\
\mathrm{df} \\
t \\
\mathrm{df}\end{array}$ & $52^{1 \cdot 80}$ & $51^{1 \cdot 57}$ & $\begin{array}{l}2.04 \\
51\end{array}$ & $\begin{array}{l}0 \cdot 38 \\
51\end{array}$ & $\begin{array}{l}3 \cdot 77^{\star} \\
55 \\
1 \cdot 78 \\
61\end{array}$ & $\begin{array}{c}1 \cdot 04 \\
55 \\
0 \cdot 49 \\
60\end{array}$ & $\begin{array}{l}3.07^{\star} \\
55^{1.02} \\
60\end{array}$ & $\begin{array}{l}0 \cdot 88 \\
55 \\
1 \cdot 43 \\
60\end{array}$ & $\begin{array}{c}3 \cdot 10^{\star} \\
54 \\
1 \cdot 14 \\
61 \\
0 \cdot 69 \\
64\end{array}$ & $\begin{array}{c}2 \cdot 32^{\star} \\
54 \\
0 \cdot 69 \\
59 \\
1 \cdot 24 \\
63\end{array}$ & $\begin{array}{l}3 \cdot 15^{\star} \\
54 \\
1 \cdot 17 \\
59 \\
0 \cdot 18 \\
63\end{array}$ & $\begin{array}{c}3 \cdot 79 \star \\
54 \\
0 \cdot 63 \\
59 \\
2 \cdot 27 \\
63\end{array}$ & $\begin{array}{c}6 \cdot 05^{\star} \\
40 \\
3 \cdot 99^{\star} \\
46 \\
2 \cdot 71^{\star} \\
50 \\
3 \cdot 29^{\star} \\
49\end{array}$ & $\begin{array}{l}7 \cdot 02^{\star} \\
40 \\
4 \cdot 24^{\star} \\
45 \\
4 \cdot 83^{\star} \\
49 \\
3 \cdot 74^{\star} \\
48\end{array}$ & $\begin{array}{c}8 \cdot 18^{\star} \\
40 \\
5 \cdot 56^{\star} \\
45 \\
4 \cdot 53^{\star} \\
48 \\
4 \cdot 20^{\star} \\
48\end{array}$ & $\begin{array}{l}4 \cdot 63^{\star} \\
40 \\
3 \cdot 00^{\star} \\
45 \\
4 \cdot 34^{\star} \\
48 \\
3 \cdot 07^{\star} \\
48\end{array}$ \\
\hline
\end{tabular}

*Indicates that a $t$ test between the mean value for this group and the one in the left-hand column shows a difference with a probability $\mathrm{p}<0 \cdot 02$.

of the PERG, in 40 eyes additional PERG recordings were made within 4 weeks of the first. The eyes thus tested were drawn in equal numbers from all the groups described above. The conditions for testing the time of day and the technique were the same at each visit. The technicians conducted the test at random and were unaware of the previous results.

\section{Results}

The cohort investigated and the results of the first test are shown in Tables $2 \mathrm{~A}$ and $2 \mathrm{~B}$. The mean age of the established glaucoma patients and glaucoma suspects was 55 years: the mean age of the normals was 41 . The small difference in the ages will make no significant change to the results. It has been shown that below the age of 70, the PERG amplitude changes little with age. ${ }^{27} 28$ The PERG is a biphasic response with a cornea positive wave peaking at around $50 \mathrm{~ms}$ after the stimulus and a cornea negative wave at about $95 \mathrm{~ms}$. We have derived four parameters from the recording, - that is, P50 $(\mu \mathrm{V}), \mathrm{N} 95$, $(\mu \mathrm{V})$, the total PERG amplitude $(\mathbf{N}+\mathbf{P})$, and the ratio N/P. For eyes with established glaucoma the mean values of all these parameters are smaller than for normals. In each of the glaucoma suspect groups, the mean P50, N95 and $(\mathrm{N}+\mathrm{P})$ are smaller than for normal subjects. The difference between the normal eye values and the values of the eyes in the suspect groups is greatest for the high risk and is least for the low risk group. The mean results and standard deviations for cohort using all the parameters of the PERG are shown in Tables $2 \mathrm{~A}$ and $2 \mathrm{~B}$. Table $2 \mathrm{~A}$ shows the results for right eyes only and Table $2 \mathrm{~B}$ shows those for left eyes only. A statistical analysis was carried out on the results obtained from the right eyes of all patients in the cohort (Table 3). Table 3 shows the results for each parameter of the PERG tested. In this table tests have been done between each group and the starred values are highly significant. Eyes with established glaucoma have PERG parameters which are significantly different from all the other groups of eyes tested. The ' $t$ ' values are very high. For the high risk suspect eyes, all parameters of the measured PERG differ highly significantly from normals and the highest $t$ value corresponding to the most significant difference is for N/P. For medium risk eyes, both P50 and $(\mathrm{N}+\mathrm{P})$ are significantly different from normal values. The $t$ value for $(\mathrm{N}+\mathrm{P})$ in low risk eyes is different from normal eyes at the $5 \%$ level of significance. ${ }^{29} \mathrm{An}$ analysis corresponding to that shown in Table 3 was also performed for the data on left eyes, with similar results. Left eye results are not given in Table 3 because of this. The differences between the grouped data for right and left eyes were small, providing the data related to the risk class. The largest differences between the mean values for right and left eyes were seen in the high risk suspect groups, but they were not significant using $t$ tests. (For P50 $t=0.88$ and for $(\mathrm{N}+\mathrm{P}) t=1 \cdot 55, \mathrm{df}=62)$.

Thus, in grouped data, the amplitude of the PERG reflects the progress of the condition. It should be noted that for the established glaucoma eyes the mean IOP is 17.4 (SD 3.76$) \mathrm{mm} \mathrm{Hg}$, lower than in the low risk OHT group (18.7 (SD 5.7)). This would be expected since all glaucoma patients were treated. In the high and medium risk OHT patients, some are treated, but in most cases pressure is considerably raised. The mean level is 24.0 (SD 4.8$) \mathrm{mm} \mathrm{Hg}$. The results therefore indicate a correlation between glaucomatous damage and the PERG amplitude, rather than a correlation between increase in pressure and the PERG, or some other interfering variable such as poor vision hindering cooperation in the glaucoma patients.

In persons with asymmetrical glaucoma, the PERG parameters differ in amplitude but within a risk class the results from the right and left eyes of this cohort were very similar, which suggests that the results from the two eyes are largely independent and related to the severity of the disease. The analysis shows that the reduction in PERG parameters progresses with risk factors.

In order to assess which of the PERG parameters are most effective at detecting glaucomatous damage, scatter diagrams plotting N95 versus $P 50(N+P)$ versus $N / P$ and $(N+P)$ versus $\mathrm{N} / \mathrm{N}+\mathrm{P}$ for 47 normal eyes and 31 glaucoma eyes were constructed (Figs 2, 3, and 4 respectively). Figure 2 shows that P50 alone is quite a good discriminator of glaucoma although there is some overlap between normal and glaucomatous eyes. Better discrimination between normal eyes and glaucomatous eyes is seen in Figure 3. The parameter $(\mathrm{N}+\mathrm{P})$ allows better separation of the two populations than P50 alone. If a value of $(\mathrm{N}+\mathrm{P})$ of $2 \cdot 7 \mu \mathrm{V}$ is chosen 29 of 31 glaucoma eyes have $(\mathrm{N}+\mathrm{P})$ values below this and all the normal eyes have $(\mathrm{N}+\mathrm{P})$ values above. The ratio of N/P is not such a good discriminator, although there is a definite trend for glaucomatous eyes to have smaller N/P values than normal eyes. A more mathematically correct ratio $(\mathrm{N} / \mathrm{N}+\mathrm{P})$ was chosen and plotted against $(\mathrm{N}+\mathrm{P})$ in Figure 4. However this ratio was no better a discriminator than $N / P$. In summary, in this cohort, the parameter $(\mathrm{N}+\mathrm{P})$ allows the best 


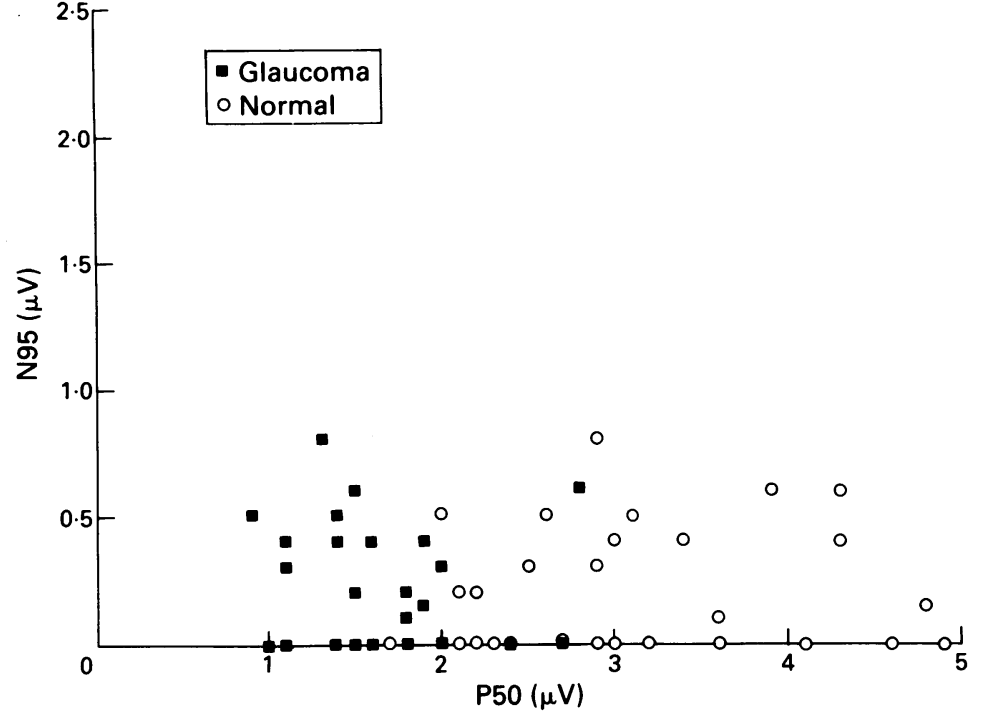

Figure 2 Discrimination of normal eyes from glaucomatous eyes. Scatter diagram of P50 values versus $N 95$.

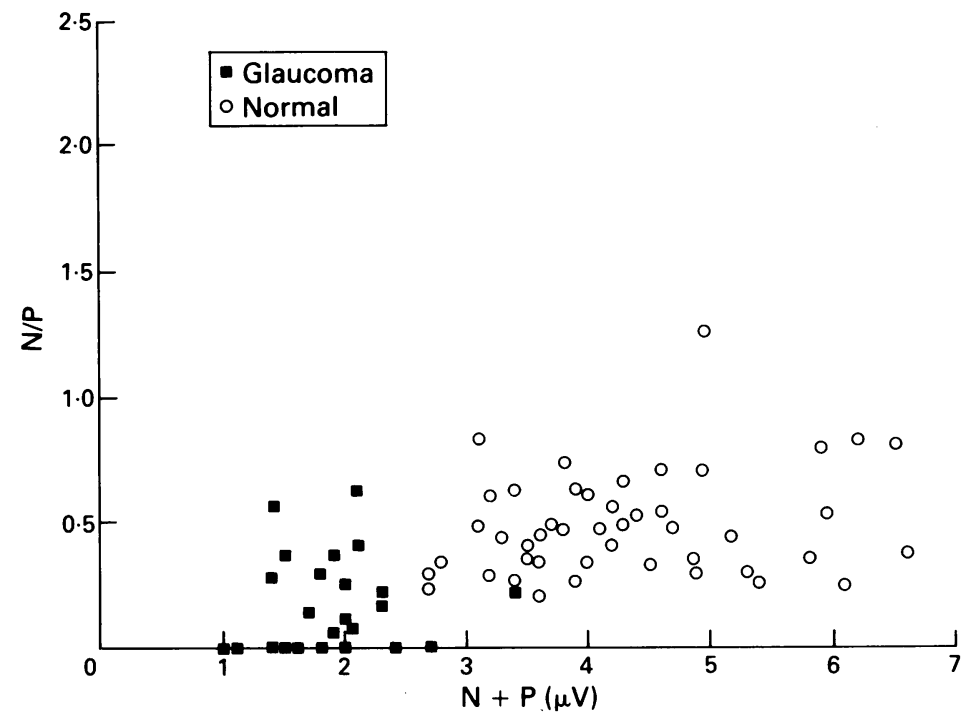

Figure 3 Discrimination of normal eyes from glaucomatous eyes using $N+P$ versus $N / P$ as parameters.

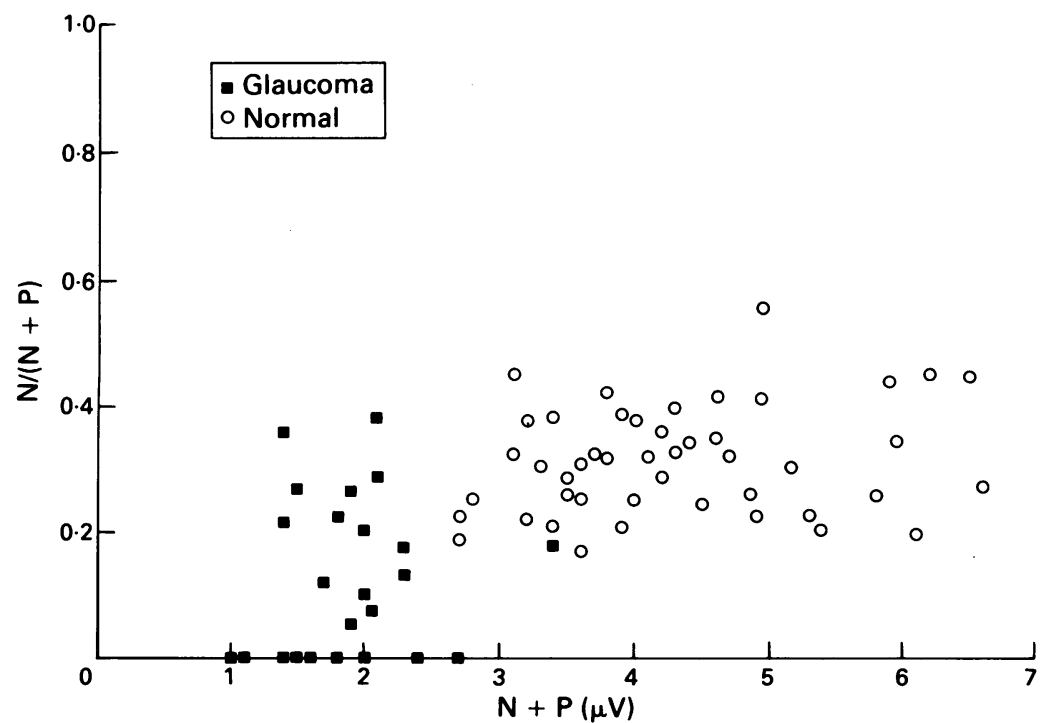

Figure 4 Discrimination of normal eyes from glaucomatous eyes using $N+P$ and $N /(N+P)$ as parameters. discrimination between glaucomatous and normal eyes.

Table 4 shows the mean PERG parameters for each group of eyes for the first and second visits. The second test occurred 6 months after the first and these second test results might be expected to give an indication of progression over time. It can be seen that the differences between the groups of eyes which were apparent on the first test are reproduced on the second test. In the high risk suspect eyes and established glaucomatous eyes, there is an overall decrease in the mean amplitude of the PERG. It can be seen that there are very small differences between the successive visits. For the medium and low risk groups the largest proportional decline is in the N95 measurement, indicating this may be preferentially affected in the early stages of OHT and glaucoma.

\section{RETINAL AREA TESTED}

Following Watanabe et $a l,{ }^{30}$ we recently investigated the central and paracentral components of the PERG in our cohort, using 'steady state' PERGs. Sixty six persons gave useful results on 130 eyes. These results were obtained between August and December 1990. Table 5 shows that the differences described between risk classes for the transient PERG are reproduced for the steady state ERG. The ratios between steady state and transient voltages are not significantly different for any class. The contribution of the central $11^{\circ}$ of the retina is about equal to that of the remaining $75 \%$ of the screen, for each risk class. The apparent relative increase of the surround response in the glaucoma patients is not significant. Watanabe et $a l^{30}$ who dealt with a smaller sample, and compared controls to eyes with established glaucoma, obtained a different result: the response from the peripheral retina decreases more with disease. Our own work, with luminance and colour contrast sensitivity. ${ }^{23}{ }^{31}$ suggested to us that the peripheral retinal PERG would be more affected in the glaucoma patients than others: however, this expectation has not been fulfilled. A possible explanation is that the amplitude of the PERG is so small in glaucoma, especially when the macula and perimacular regions are not stimulated, that the contamination of the responses by noise becomes more important.

INDIVIDUAL RESULTS

It can be seen in Tables 2 and 5 that the standard deviations of the PERGs are about $25 \%$ of the mean values. It was decided to assess carefully the reproducibility of the PERG. Test-retest investigation of the PERG was carried out by repeating tests on 40 patients' eyes within 4 weeks of the first test. The eyes thus tested consisted of equal numbers from each of the three groups and from normal and glaucoma groups. On the first occasion, 16 eyes had abnormal PERGs, and 24 normal responses. The definition of abnormality was $(\mathrm{N}+\mathrm{P})<2 \cdot 7$, a criterion derived from analysis of all the PERGs recorded, which is further explained in the next section. The mean $(\mathrm{N}+\mathrm{P})$ for the first test was 
Table 4 A comparison of the results obtained for various $P E R G$ parameters (in $\mu V$ ) in first and second visits. (Note the small decreases that occur on the second visit, showing further departures from normal)

\begin{tabular}{|c|c|c|c|c|}
\hline & \multirow{2}{*}{$\begin{array}{l}\text { 1st visit } \\
\text { Mean }\end{array}$} & \multirow[b]{2}{*}{$S D$} & \multicolumn{2}{|c|}{ 2nd visit } \\
\hline & & & Mean & $S D$ \\
\hline P50 & & & & \\
\hline Glaucoma & 1.60 & $(0 \cdot 49)$ & 1.61 & $(0.45)$ \\
\hline High risk & 2.30 & $(0.69$ & $2 \cdot 10$ & $(0 \cdot 60)$ \\
\hline Medium risk & $2 \cdot 24$ & $(0.71)$ & 2.05 & $(0.57)$ \\
\hline $\begin{array}{l}\text { Low risk } \\
\text { N95 }\end{array}$ & $2 \cdot 56$ & $(0.71)$ & $2 \cdot 41$ & $(0.65)$ \\
\hline Glaucoma & $0 \cdot 24$ & $(0 \cdot 28)$ & $0 \cdot 20$ & $(0 \cdot 19)$ \\
\hline High risk & 0.75 & $(0.58)$ & 0.66 & $(0.60)$ \\
\hline Medium risk & $1 \cdot 19$ & $(0 \cdot 78)$ & 0.83 & $(0.60)$ \\
\hline Low risk & $1 \cdot 04$ & $(0.78)$ & 0.91 & $(0 \cdot 70)$ \\
\hline $\begin{array}{l}\mathrm{N} / \mathrm{P} \\
\text { lauma }\end{array}$ & & $(0 \cdot 17)$ & & \\
\hline Glaucoma & $\begin{array}{r}0.14 \\
0.25\end{array}$ & (0.1/) & 0.13 & $(0 \cdot 16)$ \\
\hline High risk & 0.35 & $(0 \cdot 27)$ & $0 \cdot 35$ & $(0.37)$ \\
\hline Medium risk & 0.57 & $(0 \cdot 37)$ & 0.45 & $(0.34)$ \\
\hline $\begin{array}{l}\text { Low risk } \\
(\mathrm{N}+\mathrm{P})\end{array}$ & 0.44 & $(0 \cdot 34)$ & 0.41 & $(0 \cdot 34)$ \\
\hline Glaucoma & $1 \cdot 84$ & $(0.65)$ & $1 \cdot 82$ & $(0 \cdot 45)$ \\
\hline High risk & $3 \cdot 12$ & $(1.08)$ & $2 \cdot 68$ & $(0.90)$ \\
\hline Medium risk & 3.44 & $(0.77)$ & $2 \cdot 89$ & $(0.88)$ \\
\hline Low risk & 3.60 & $(0 \cdot 88)$ & $3 \cdot 31$ & $(1.03)$ \\
\hline
\end{tabular}

2.98 (SD 1.21) $\mu \mathrm{V}$ and for the second, 3.0 (SD $0.97) \mu \mathrm{V}$. The large standard deviations reflect the inter-individual differences in PERG amplitude. The average difference between the two successive readings was $15 \%$ of the mean. Eighteen eyes gave smaller responses on the second visit, and 19 larger: in the remaining three, the recordings were identical within the precision of measurement $(0 \cdot 1 \mu \mathrm{V})$. In 37 of 40 , the difference between the two readings made no difference between the classification of normal and abormal. In the remainder, in two cases, one of the PERG records was borderline normal/ abnormal. In the other case the response amplitude appeared to increase from 1.8 to 3.9 $\mu \mathrm{V}$. The test-retest results are illustrated on a scatter diagram (Fig 5). This illustrates the good

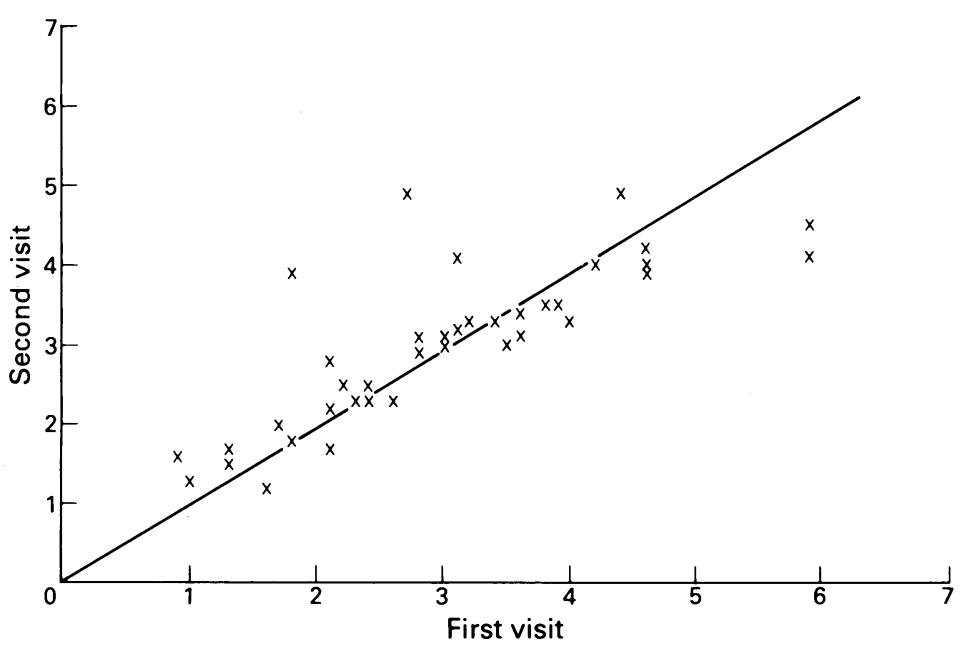

Figure 5 Scattergram illustrating results of $N+P$ values (in $\mu V$ ) for test-retest PERGs on 40 eyes. Regression coefficient of solid line $=0 \cdot 80$

Table 5 A comparison of transient and steady-state PERG amplitudes (in $\mu V)$ in a selected population

\begin{tabular}{lllllll}
\hline Class & $\begin{array}{l}\text { Number } \\
\text { of eyes }\end{array}$ & $\begin{array}{l}\text { Number } \\
\text { of patients }\end{array}$ & $\begin{array}{l}\text { Transient } \\
(N+P)\end{array}$ & $\begin{array}{l}\text { Steady } \\
\text { state }\end{array}$ & $\begin{array}{l}\text { Steady/ } \\
\text { transient }\end{array}$ & $\begin{array}{l}\text { Surrounding/ } \\
\text { total }\end{array}$ \\
\hline Glaucoma & 10 & 5 & 1.58 & 1.22 & 0.78 & 0.64 \\
High risk & 42 & 21 & 3.09 & 1.97 & 0.64 & 0.52 \\
Medium risk & 57 & 29 & 2.95 & 1.99 & 0.69 & 0.47 \\
Low risk & 21 & 11 & 3.55 & 2.32 & $0 \cdot 70$ & 0.50 \\
\hline
\end{tabular}

The values for $(\mathrm{N}+\mathrm{P})$ can be compared with those in the entire cohort (Tables 2 and 4 ). The ratio between steady state and transients and the voltage response of the $75 \%$ of the peripheral retina compared to the total, are shown in the last two columns correlation between the two sets of values. The regression coefficient $=0 \cdot 80$. The formal calculation of the reliability coefficient (1-[square of SD of differences]/square of SD of first measurement $)=0 \cdot 82$. Thus test-retest variability should not cause significant differences in the results.

The correlation between clinical estimates of normality and estimates derived from the PERG depends upon the PERG criteria used to divide eyes into normal and abnormal groups.

To attack this problem, we sorted out results, using the facilities of the spreadsheet, using various criterion levels to separate 'normal' from 'abnormal'. Results for the entire cohort are shown in Figures 6, 7, 8 and 9. It can be seen that for eyes of patients with established glaucoma, the total peak-to-peak amplitude of the PERG is nearly always lower than for all the normals; for the high risk suspect eyes, the overlap is considerable, and for low risk it is nearly complete. By adopting various criteria for normality, one can alter the sensitivity and specificity of the test, as shown in Table 6 . If a criterion of $\mathrm{P} 50<1.8 \mu \mathrm{V}$ is chosen, $2 \%$ of normal eyes will be considered abnormal, but only $69 \%$ of eyes with established glaucoma will be detected. More convincingly, if abnormality is defined as $\mathrm{N} 90<0 \cdot 6 \mu \mathrm{V}$, then $2 \%$ of false positives will be detected, and $84 \%$ of all glaucomatous eyes will be abnormal.

Better criteria can be obtained if several measurements are made on the PERG. Our data show that for one determination, abnormality is best defined as $(\mathrm{P}+\mathrm{N})<2 \cdot 7 \mu \mathrm{V}$, and $\mathrm{N} / \mathrm{P}<0 \cdot 7$. Under such circumstances, no eye from the control group is considered as abnormal, and $94 \%$ of eyes of patients with established glaucoma are detected.

The same result can be applied to the data from ocular hypertensives, and there it can be seen that a much lower proportion are considered abnormal, and more than twice as many eyes at severe risk have abnormal PERGs as those in lower risk groups.

\section{SUBSEQUENT VISITS}

Glaucoma suspects have repeated field tests, and only when a possible defect is subsequently confirmed is it considered that the patient has changed from OHT to established glaucoma. In just the same way, we can combine the results of two or more PERG tests. If abnormality is defined by the PERG falling below $(\mathrm{P}+\mathrm{N})<2 \cdot 7$ and $N / P<0.7$ on one occasion during the entire investigation, the results are as shown in Figure 10: the main difference is that now, $100 \%$ of normal eyes can be distinguished from $100 \%$ of the eyes of patients with established glaucoma.

\section{Discussion}

The present results extend and confirm our (and other) prior reports of PERG abnormalities in glaucoma and ocular hypertension. In particular, we have carried out a masked study in a relatively sizeable cohort for up to 2 years, and have been able to observe and correlate changes in the PERG with the clinical condition. The number 
of suspects and normals tested is larger than in our previous report and the follow-up time is at least 1 year in all cases. In addition, while in previous work patients' results have been compared with previous established normal values, we have attempted to establish which criteria would be of greatest clinical value in our cohort. We have demonstrated that the PERG is persistently abnormal in eyes with established

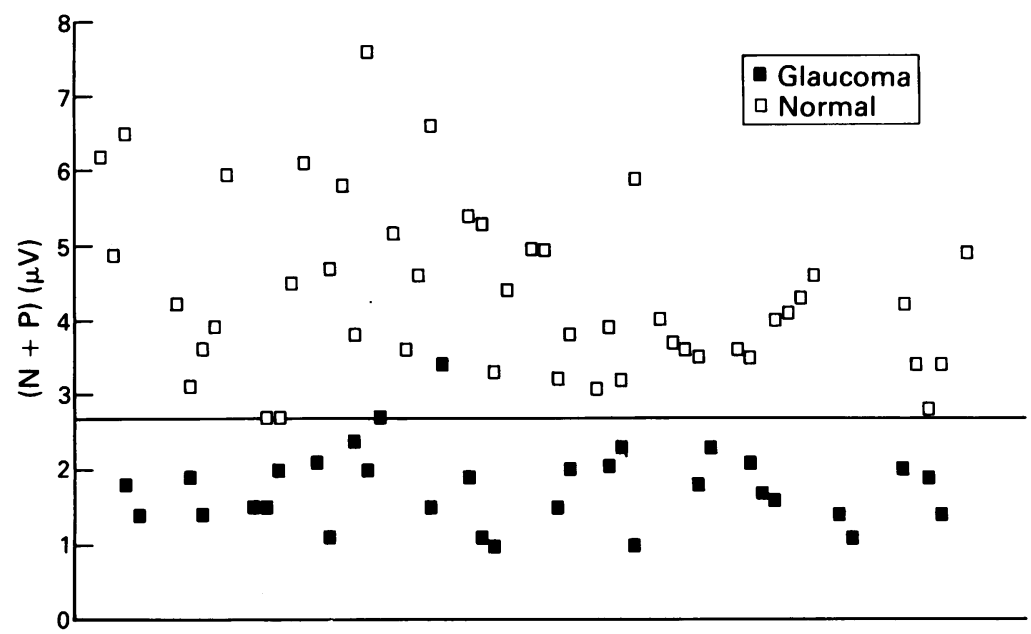

Figure 6 Individual results for normal subjects compared with patients with established glaucoma. The magnitude of $(N+P)$ is plotted on the ordinate. Each interval on the abscissa gives the result from a different eye. Results from both left and right eyes are shown.

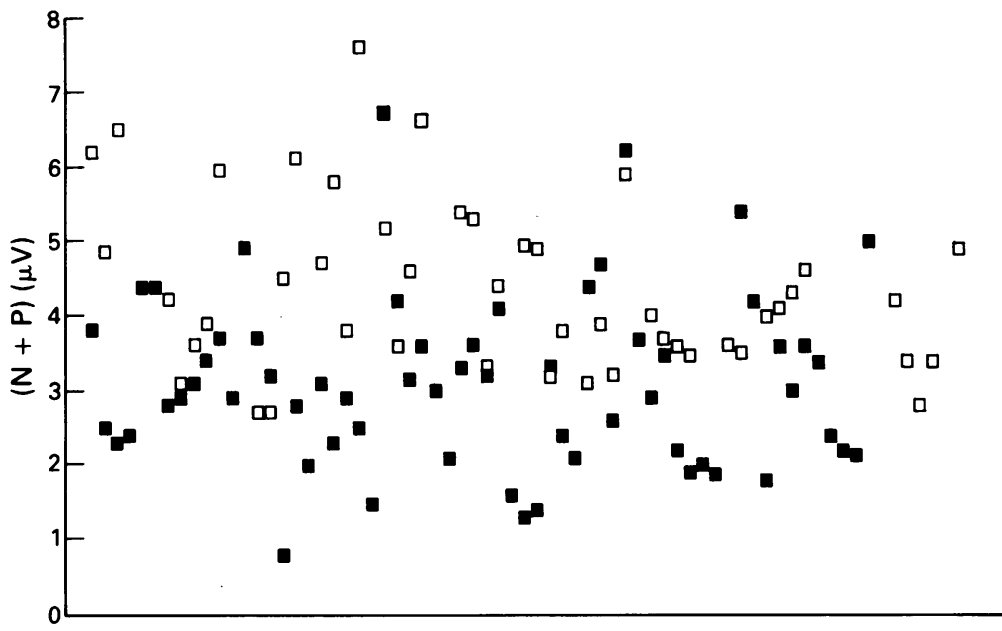

Figure 7 Individual results for normal subjects (open squares) compared with patients in the high risk group (filled squares). Conventions as in Fig 6.

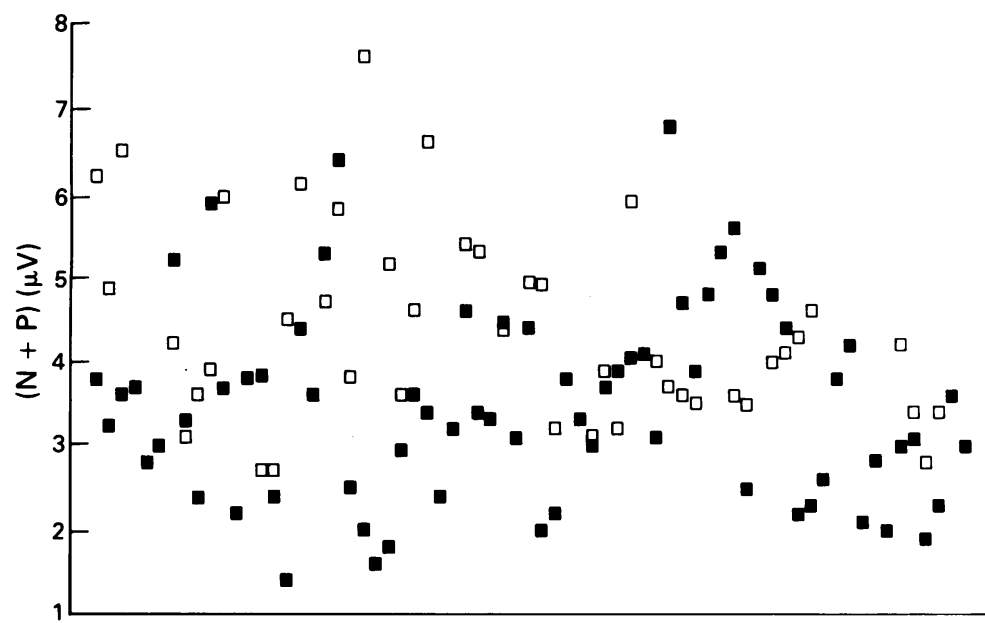

Figure 8 Individual results for normal subjects (open squares) compared with patients in the medium risk group (filled squares). Conventions as in Fig 6. glaucoma. In our cohort, using as a criterion of abnormality $(P+N)<2.7$ and $N / P<0.7$, we were able to separate $94 \%$ of such eyes from the normal group with one PERG test. With two tests we were able to differentiate $100 \%$ of the glaucomatous eyes from normals. Although this sensitivity and specificity is striking and compares well with automated perimetry, it must be treated with some caution. Our sample size is relatively small and our recruitment criteria removed patients with early cataract or macular degeneration who would normally be included in a glaucoma clinic. Nevertheless the result is objective in a sense that a field test is not. It is as easy for the patient and at least in our cohort seems as reliable as perimetry. Therefore it is likely that serial PERGs can have a place in management of glaucoma patients and suspects.

Our results also demonstrate that glaucoma suspects' eyes show a reduction in their PERG recordings. All our glaucoma suspect groups had smaller mean PERGs than the normals, although this was significant for the high risk group only. The reduction in the PERG of suspects eyes was notable because of the proportionately greater reduction in the N95 component. This had been noted in our previous report and suggests the N95 wave is selectively damaged by the glaucomatous process.

The trial was conducted so that clinical data and the PERG results were collected independently. However the reduction in the PERG mirrored the degree of risk assessed clinically. Thus, high risk suspect eyes had three times as many abnormal PERGs as the low risk eyes; the PERG abnormalities were reproduced on testing at the second visit. This suggests that abnormal PERGs truly reflect abnormal retinal function in glaucoma suspects' eyes. This abnormality was detected while field tests, which are currently used to monitor function, were completely normal. The reasons for the sensitivity of the PERG to retinal or optic nerve damage are not fully understood. Several factors must contribute: the amplitude of the response is due to sampling from a large retinal area, so point-topoint variation in sensitivity is averaged out. Furthermore there is some evidence that the PERG is produced by larger diameter retinal ganglion cells ${ }^{32}$ which are known to be affected earlier than small ganglion cells in the evolution of glaucoma. ${ }^{33}$ The steady state or peripheral retinal responses in our hands are no more effective criteria, though our experience of them is not so extensive. These results are of interest insofar as they may give some clues about the underlying pathology. For example, the P50 response is affected in glaucoma although it is generated in part by the interneurons or glia of the retina, and only partly by ganglion cells: this suggests that increased pressure may do more than damage optic axons near the cribriform plate.

Although the PERG is an objective test, the voltage is small and the recordings contaminated by noise and artefacts. We have used various methods of stimulation and recording in order to identify which is the most efficient method. However, no one method seems to have any obvious superiority. Our results with test-retest 


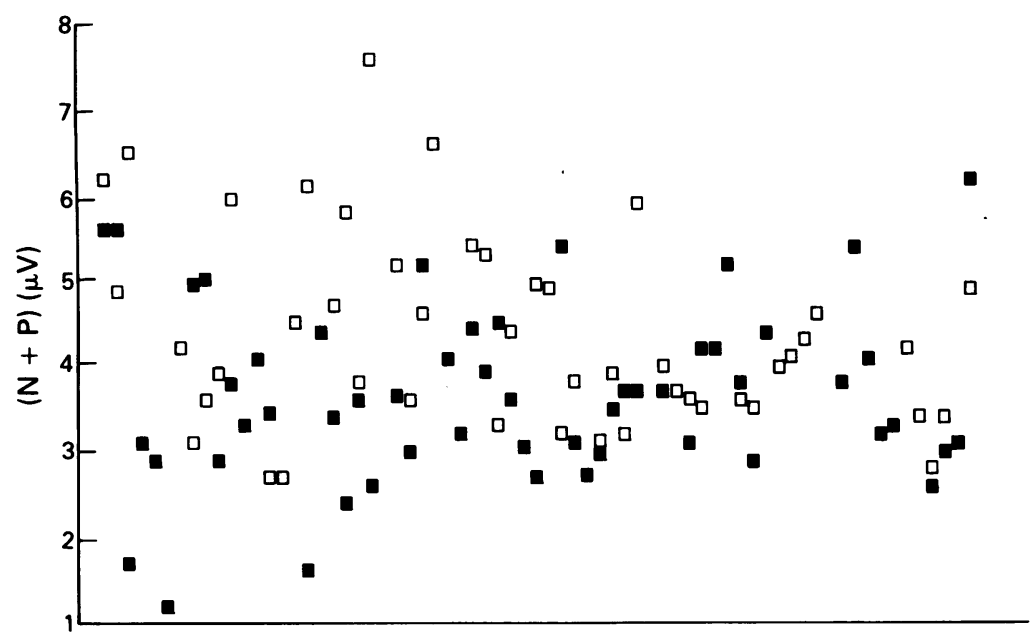

Figure 9 Individual results for normal eyes (open squares) compared to eyes in the low risk group (filled squares). Conventions as in Fig 6.

Table 6 Sensitivity and specificity obtained for various criteria of abnormality of the PERG

\begin{tabular}{|c|c|c|c|c|c|}
\hline \multirow[b]{2}{*}{ Criterion } & \multicolumn{5}{|c|}{ Percentage of eyes considered abnormal, using different criteria } \\
\hline & Controls & Glaucoma & High risk & Medium risk & Low risk \\
\hline $\begin{array}{l}P 50 \\
\quad<2 \cdot 2 \\
<2 \cdot 0 \\
<1 \cdot 8 \\
<1.7\end{array}$ & $\begin{array}{r}13 \\
2 \\
2 \\
0\end{array}$ & $\begin{array}{l}90 \\
88 \\
69 \\
69\end{array}$ & $\begin{array}{l}47 \\
38 \\
29 \\
19\end{array}$ & $\begin{array}{l}53 \\
42 \\
15 \\
20\end{array}$ & $\begin{array}{l}20 \\
15 \\
17 \\
11\end{array}$ \\
\hline $\begin{array}{l}\text { N95 } \\
<0.8 \\
<0.7 \\
<0.6 \\
<0.5 \\
(\mathrm{P} 50+\mathrm{N} 95)\end{array}$ & $\begin{array}{r}13 \\
6 \\
2 \\
0\end{array}$ & $\begin{array}{l}94 \\
91 \\
84 \\
75\end{array}$ & $\begin{array}{l}50 \\
43 \\
34 \\
33\end{array}$ & $\begin{array}{l}25 \\
16 \\
16 \\
13\end{array}$ & $\begin{array}{l}44 \\
38 \\
37 \\
13\end{array}$ \\
\hline $\begin{array}{l}<3.0 \\
<2 \cdot 7 \\
<2 \cdot 5 \\
<2 \cdot 3\end{array}$ & $\begin{array}{l}6 \\
0 \\
0 \\
0\end{array}$ & $\begin{array}{l}94 \\
94 \\
94 \\
88\end{array}$ & $\begin{array}{l}55 \\
43 \\
38 \\
30\end{array}$ & $\begin{array}{l}29 \\
24 \\
17 \\
28\end{array}$ & $\begin{array}{l}28 \\
18 \\
16 \\
13\end{array}$ \\
\hline $\begin{array}{l}\mathrm{P}+\mathrm{N}<2.7+\mathrm{N}<0.9 \\
\mathrm{P}+\mathrm{N}<2.7+\mathrm{N}<0.7 \\
\mathrm{P}+\mathrm{N}<2.7+\mathrm{N} / \mathrm{P}<0.7 \\
\mathrm{P}+\mathrm{N}<2.7+\mathrm{N} / \mathrm{P}<0.5\end{array}$ & $\begin{array}{l}0 \\
6 \\
0 \\
0\end{array}$ & $\begin{array}{l}94 \\
97 \\
94 \\
84\end{array}$ & $\begin{array}{l}34 \\
65 \\
29 \\
53\end{array}$ & $\begin{array}{l}15 \\
31 \\
13 \\
29\end{array}$ & $\begin{array}{l}17 \\
41 \\
13 \\
39\end{array}$ \\
\hline
\end{tabular}

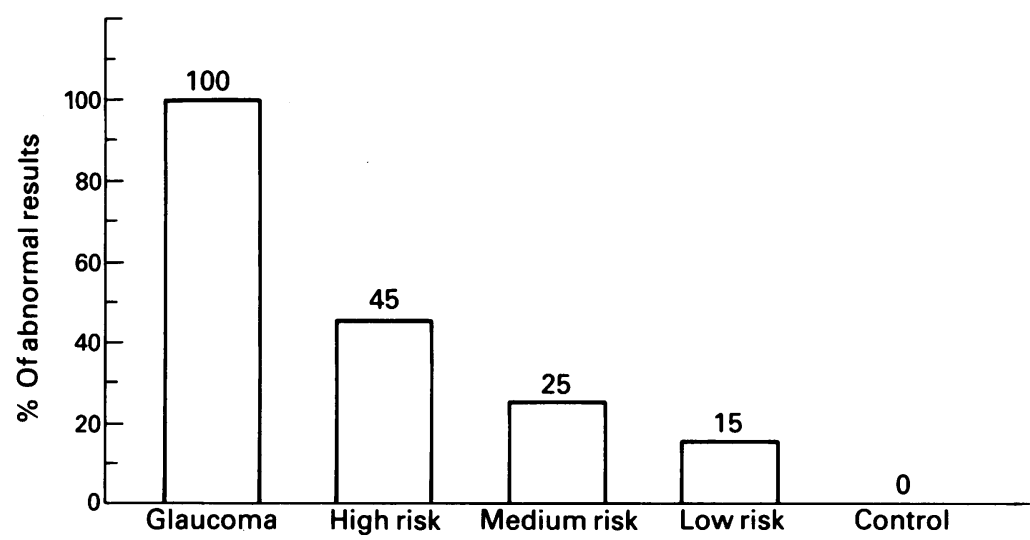

Figure 10 Sensitivity and specificity of the PERG. The criteria for abnormality were that $(N+P)$ should be $<2 \cdot 7 \mu V$, and N/P $<0.7$ on at least one occasion. The numbers above the bars give the percentage of abnormalities found. Database as for Table 3 . The results refer to individual eyes.

show acceptable reproducibility: although there is some variability in each individual's results on repeat testing, this is only very infrequently of a degree which would cause a previously normal result to be subsequently classified as abnormal, or vice versa. We have reported the results of PERG tests on a sizeable cohort followed for 1 year. The follow-up of these patients is continuing; this will provide further information on the natural evolution of glaucomatous disease as monitored by the PERG. It will allow us to correlate the PERG results with the subsequent development of perimetric defects and enable us to determine whether treatment of glaucoma suspects with topical $\beta$ blockers has an effect on the PERG.

In summary, the PERG is as quick to perform as a test of the visual field with automated perimetry. It is subject to some variability, but this is of an acceptable degree. The PERG convincingly separates all persons with field defects from normals and also demonstrates that a proportion of suspects have reduced responses. The proportion of abnormal PERG mirrors the degree of risk of the suspects. Our experience suggests than an abnormal PERG is an indicator of retinal damage during the phase of 'preglaucoma' before any scotoma can be detected by perimetry. Logic suggests that the PERG could be used for screening in this population, but to demonstrate its value in such a role would require a larger and more prolonged controlled clinical trial.

We thank Professor Joaquim Maia and $\mathrm{Mr} \mathrm{R}$ Wormald for statistical analyses and Mr Redmond Smith for a critical reading of the manuscript. This work was supported by Fellowships from The manuscript. This work was supported by Fellowships from European Scientific Exchange Scheme of the Royal Society (WS) and the Frost Foundation (BM, E O'D and F O'S). GBA acknowledges support from the Wellcome Foundation and Wolfson Foundation. We thank Mrs S Gunderwardena, $\mathrm{Mr}$ Owoluwe, and Mr D Perry for technical help, and all the members of the Glaucoma Department, Moorfields Eye Hospital for their support.

1 Quigley HA, Addicks EM, Green WR. Optic nerve damage in human glaucoma, III: quantitative correlation of nerve fibre loss and visual field defect in glaucoma, ischaemic neuropathy, papilledema, and toxic neuropathy. Arch Ophthalmol 1982; 100: $135-46$.

2 Sorensen PN, Nielsen NV, Norskov K. Ocular hypertension : a 15 year follow-up. Acta Ophthalmol $(K b h)$ 1978; 56: 36372 .

3 Kitazawa Y, Aoki S, Suzuki M, Nishioka K. Untreated ocular hypertension : a long term prospective study. Arch Ophthal-

4 Kass MA, Gordon MO, Hoff MR, et al. Topical timolol administration reduces the incidence of glaucomatous damage in ocular hypertensive individuals. Arch Ophthalmol 1989; 107: 1590-8

5 Krug JH, Hertzmark E, Remis LL, Epstein D. Long term study of timolol versus no treatment in the management of glaucoma suspects. Invest Ophthalmol Vis Sci 1987; 28 (suppl): 148.

6 Caprioli J, Miller J. Measurement of relative nerve fibre laver surface height in glaucoma. Ophthalmologv 1989; 96: 63341 .

7 Hitchings RA, Pooninwamy D, Poplar N, Sheth GP. Retinal nerve fibre layer photography in glaucomatous patients. Eye 1987; 1: 621-5

8 Takamoto T, Schwartz B. Photogrammetric measurement of nerve fiber layer thickness. Ophthalmologv (Rochester) 1989 96: 1315-9.

9 Wanger $P$, Persson HE. Pattern reversal electroretinograms in unilateral glaucoma. Invest Ophthalmol Vis Sci 1983; 24 749-53.

10 Papst N, Bopp M, Schnaudigel OE. Pattern electroretinogram and visually evoked cortical potentials in glaucoma. Graefes Arch Clin Exp Ophthalmol 1984; 222: 29-33.

11 Papst N, Bopp M, Schnaudigel OE. The pattern evoked electroretinogram associated with elevated intraocular pressure. Graefes Arch Clin Exp Ophthalmol 1984;222:34-7.

12 Van Lith G, Ringens P, DeHeer LJ. Pattern electroretinogram and glaucoma. Dev Ophthalmol 1984; 9: 133-9.

13 Wanger $P$, Persson HE. Pattern-reversal electroretinograms and high-pass resolution perimetry in suspected or early

14 Bobak P, Bodis-Wollner I, Harnois C, et al. Pattern electroretinograms and visual evoked potentials in glaucoma and multiple sclerosis. Am 7 Ophthalmol 1983; 96: 72-83.

15 Howe JW, Mitchell KW. Simultaneous recording of pattern electroretinogram and visual evoked cortical potential in group of patients with chronic glaucoma. Doc Ophthalmo 1984; 40: 101-7.

16 Porciatti V, Falsini B, Brunori S, Colotto A, Moretti G Pattern electroretinogram as a function of spatial frequency in ocular hypertension and early glaucoma. Doc Ophthalmol 1987; 65: 349-55.

17 Bach H, Hiss P, Rover J. Check-size specific changes of pattern electroretinogram in patients with early open-angle glaucoma. Doc Ophthalmol 1988; 69: 315-22. 
18 Van den Berg TJTP, Riemslag FCC, de Vos GWGA, Verduyn Lunel HFE. Pattern ERG and glaucomatous field defects. Doc Ophthalmol 1985; 61:335-41.

19 Berninger T, Schuurmans RP. Spatial tuning of the pattern ERG across temporal frequency. Doc Ophthalmol 1985; 61: ERG $17-25$

20 Holder GE. Significance of abnormal pattern electroretinography in anterior visual pathway dysfunction. $\mathrm{Br} \mathcal{F}$ Ophthalmol 1987; 71 : 166-71

21 Ohta H, Tamura T, Kawasaki K, Yonemura D. Negative wave in human pattern ERG and its suppression glaucoma. Nippon Ganka Gakkai Zasshi 1986; 90: 882-6.

22 Weinstein GW, Arden GB, Hitchings RA, Ryan S, Calthorpe MC, Odom JV. The pattern electroretinogram (PERG) in 106: $923-8$.

23 Gunduz K, Arden GB, Perry S, Weinstein G, Hitchings RA. Colour vision defects in ocular hypertension and glaucoma: quantification with a computer driven colour television system. Arch Ophthalmol 1988; 108: 929-35.

24 Hamil TR, Post RB, Johnson CA, et al. Correlation of colour vision deficits and observable changes in the optic disc in a vision deficits and observable changes in the optic disc in a
population of ocular hypertensives. Arch Ophthalmol 1984; 102: 1637-9.

25 Falcão-Reis FM, O'Sullivan F, Spillers W, Hogg C, Arden GB. Macular colour contrast sensitivity in ocular hyper- tension and glaucoma: evidence for two types of defect. $\mathrm{Br} F$ Ophthalmol 1991; 75: 598-602.

26 Yablonski ME, Zimmerman TJ, Kass MA, Becker B. Prognostic significance of optic disc cupping in ocular hypertensive patients. Am f Ophthalmol 1980; 89: 585-92.

27 Trick LR. Age related alterations in retinal function. Doc Ophthalmol 1987; 66: 35-43.

28 Arden GB, Carter RM, McFarlan A. Pattern and ganzfeld electroretinograms in macular disease. Br $\mathcal{F}$ Ophthalmol electroretinogram

29 Armitage P. Statistical methods in medical research. Blackwell: London, 1971, 267

30 Watanabe I, Iijinn $\mathrm{H}$, Tsukahara $\mathrm{S}$. The pattern electroretinogram (PERG) in glaucoma: an evaluation by relative amplitude from the Bjerrum area. Brf Ophthalmol 1990; 73 : $131-5$.

31 Tak C, Yu F, Falcao-Reis, Spileers, G B Arden. Peripheral colour contrast: a new screening test for preglaucomatous visual loss. Invest Ophthalmol Vis Sci 1991; 32: 2779-89.

32 Berninger TA, Arden GB, Hogg CR, Frumkes TE. Separable evoked retinal and cortical potentials for each major visual pathway: preliminary results. Br $\mathrm{f}$ Ophthalmol 1989; 73: pathway:

33 Quigley HA, Sanchez C, Dunkelberger H. Chronic glaucoma selectively damages large optic nerve fibres. Invest Ophthalmol Vis Sci 1987; 28: 913 . 